\title{
A função retórica Suporte em português
}

\author{
Ana Paula de Oliveira \\ Universidade Estadual Paulista "Júlio de Mesquita Filho" (UNESP), \\ São José do Rio Preto, São Paulo, Brasil \\ anapaula1309@yahoo.com.br \\ http://orcid.org/0000-0003-1718-4056
}

DOI: $\underline{\text { http://dx.doi.org/10.21165/el.v47i1.1951 }}$

\section{Resumo}

$\mathrm{O}$ trabalho que ora se apresenta tem como objetivo investigar as relações estabelecidas por orações e sintagmas iniciados por além de no português. Para tanto, analisa ocorrências de língua falada, extraídas do córpus "Português oral", organizado pelo Centro de Linguística da Universidade de Lisboa, em parceria com a Universidade de Toulouse-le-Mirail e a Universidade de Provença-Aix-Marselha, tomando como aparato teórico a Gramática Discursivo-Funcional (HENGEVELD; MACKENZIE, 2008).

Palavras-chave: Gramática Discursivo-Funcional; função retórica; além de; adição.

\section{Support Rhetorical Function in Portuguese}

\begin{abstract}
The paper now presented aims to investigate the relations established by clauses and phrases initiated by the structure além de [aside from in Portuguese]. Therefore, it assumes as theoretical apparatus the Functional Discourse Grammar (HENGEVELD; MACKENZIE, 2008), in order to analyze occurrences of spoken language, extracted from the "Português oral" [oral Portuguese] corpus, organized by the Center of Linguistics of the University of Lisbon, in partnership with the University of Toulouse-le-Mirail and the University of Provence-AixMarseille.
\end{abstract}

Keywords: Functional Discourse Grammar; rhetorical function; além de; addition.

\section{A relação de adição na literatura}

Em um estudo acerca das relações adverbiais nas línguas da Europa, Hengeveld (1998) aponta, dentre os tipos semânticos de orações adverbiais, a oração de adição, que compreende construções como "além de preparar o jantar, eu cuido do jardim" 1 " (HENGEVELD, 1998, p. 352). No entanto, uma breve apreciação acerca do tratamento dispensado à relação aditiva em português permite verificar que a tradição gramatical e os trabalhos na área da linguística pouco têm se debruçado sobre o tema. Em termos de Gramática Tradicional, a relação aditiva é considerada apenas em sua configuração oracional, no âmbito das relações coordenadas, ou seja, aquelas que relacionam dois ou mais eventos sintaticamente independentes. Segundo Kury (1987), a coordenação aditiva ocorre quando vários pensamentos coordenados estão simplesmente em sequência, ou encadeados de modo a serem introduzidos por conjunções. Ainda segundo o autor, essas relações podem ser sindéticas - quando apenas a oração aditiva é iniciada pela conjunção - como se observa em (1), em que a última oração é introduzida

\footnotetext{
${ }^{1}$ Apart from cooking dinner, I look after the garden.
} 
por $e$, ou correlatas - quando há presença da conjunção em ambas as orações, como se observa em (2):

(1) Não vê, não ouve, não fala $e$ não conhece ninguém. (Garret, VMT, 318)

(2) Quincas Borba não só estava louco, mas sabia que estava louco. (M. de Assis, BC, 379).

Outro argumento em favor de que o tratamento dispensado à relação de adição é superficial fundamenta-se na maneira como (não) são explorados os elementos que marcam essa relação, tendo em vista que as gramáticas costumam mencionar sempre as mesmas conjunções como as únicas capazes de marcar essa circunstância, o que revela uma supervalorização da forma em detrimento da função. Exemplo da adoção dessa perspectiva minimalista são os gramáticos Cunha e Cintra (2001), que se limitam a mencionar apenas as conjunções $e$ e nem como aditivas, definindo-as como aquelas que servem para ligar dois termos ou duas orações de idêntica função, como permitem observar (3) e (4):

Leonor voltou-se $e$ desfaleceu. (G. Ramos, I, 81.)

(4) Ele não me agradece, nem eu lhe dou tempo. (F. Botelho, X, 41.)

Os estudos linguísticos, por seu turno, costumam dispensar maior atenção a possíveis processos de gramaticalização envolvidos nos diferentes usos desses juntores, à natureza da relação sintática entre os elementos envolvidos na estrutura aditiva, ou ainda à pluralidade funcional de um mesmo conectivo. Dentre tais abordagens acerca do fenômeno da adição, vale citar o trabalho de Módolo (2005), que entende as construções correlatas conjuncionais - dentre elas as correlatas aditivas - como um processo particular de articulação sintática, que não se enquadra, por sua vez, nas tradicionais definições de coordenação ou subordinação. Há também trabalhos que se debruçam sobre questões como os diferentes valores semântico-discursivos do conectivo $e$, a exemplo da investigação protagonizada por Camacho (1999) acerca de estruturas coordenadas aditivas, em que o autor defende, a partir de uma abordagem funcionalcognitiva, que o conectivo $e$, como conjunção de termos ou de orações, apresenta usos discursivos que são determinados por condições pragmáticas. Em diálogo com esta análise, tem-se a investigação de Penhavel (2005), que entende o conectivo $e$ como multifuncional, tendo em vista que seu estatuto funcional é fruto de um processo de discursivização.

Adotando uma perspectiva mais próxima da que se objetiva imprimir à investigação que ora se apresenta, tem-se dois trabalhos de Oliveira (2012a, 2012b), em que a autora faz uma apreciação sobre a relação aditiva a partir da análise de orações iniciadas por além de, valendo-se de duas abordagens teóricas distintas. Na primeira delas, adotando a perspectiva de Halliday (1985) e de Mathiessen e Thompson (1988), considera as orações construídas com além de como casos de hipotaxe adverbial. Isso define, portanto, essas orações como dependentes em relação a uma oração matriz, de modo que lhe acrescentam uma circunstância, mas não mantêm com ela uma relação de constituência, uma vez que não são consideradas constituintes da oração principal, como ocorre com os processos de encaixamento.

Na segunda abordagem, norteada pela Gramática Discursivo-Funcional, na qual também se baseia o estudo que aqui propomos, Oliveira (2012b) parte das reflexões e análises iniciadas por Pérez Quintero (2002) e Hengeveld (1998) para defender a 
existência de uma oração subordinada adverbial aditiva, o que, em termos teóricos, aponta para uma construção em que há uma relação de dependência morfossintática entre um núcleo e seu modificador, característica do processo de subordinação de acordo com essa abordagem teórica. A autora considera, contudo, aspectos relacionados aos níveis representacional e morfossintático como primordiais ao entendimento desse tipo de relação, o que se distancia, de alguma maneira, da proposta da investigação que aqui se propõe no que tange ao tratamento das orações iniciadas por além de, tendo em vista que o foco que se pretende imprimir à análise das estruturas analisadas refere-se sumariamente a seu papel interacional, que determina seu papel semântico e, consequentemente, morfossintático.

\section{Aspectos teórico-metodológicos}

A Gramática Discursivo-Funcional é uma teoria capaz de explicar os fenômenos que envolvem a interação entre os níveis pragmático, semântico e morfossintático, bem como de analisar unidades menores e maiores do que a oração.

Para tanto, admite uma perspectiva de análise das estruturas linguísticas que parte da intenção do falante em direção à materialização do enunciado. Essa organização descendente, enquanto perspectiva analítico-metodológica, concretiza o princípio das teorias linguísticas de base funcional: a priorização da função em detrimento da forma.

Dessa maneira, a intenção comunicativa e suas representações mentais oriundas do Componente Conceitual são relevantes, uma vez que serão traduzidas, por meio da operação de Formulação, em representações pragmáticas e semânticas nos níveis Interpessoal e Representacional. As regras utilizadas na Formulação variam de acordo com cada língua, posto que noções semânticas e pragmáticas não são universais. O processo de Codificação, por sua vez, ocorre nos níveis Morfossintático e Fonológico e compreende as regras que convertem essas representações pragmáticas e semânticas em representações morfossintáticas e fonológicas.

Segundo Hengeveld e Mackenzie (2008), ao organizar o Componente Gramatical desse modo, a GDF leva a abordagem funcional da linguagem ao seu extremo lógico: dentro da organização descendente da gramática, a pragmática governa a semântica, a pragmática e a semântica governam a morfossintaxe, e a pragmática, a semântica e a morfossintaxe governam a fonologia. 


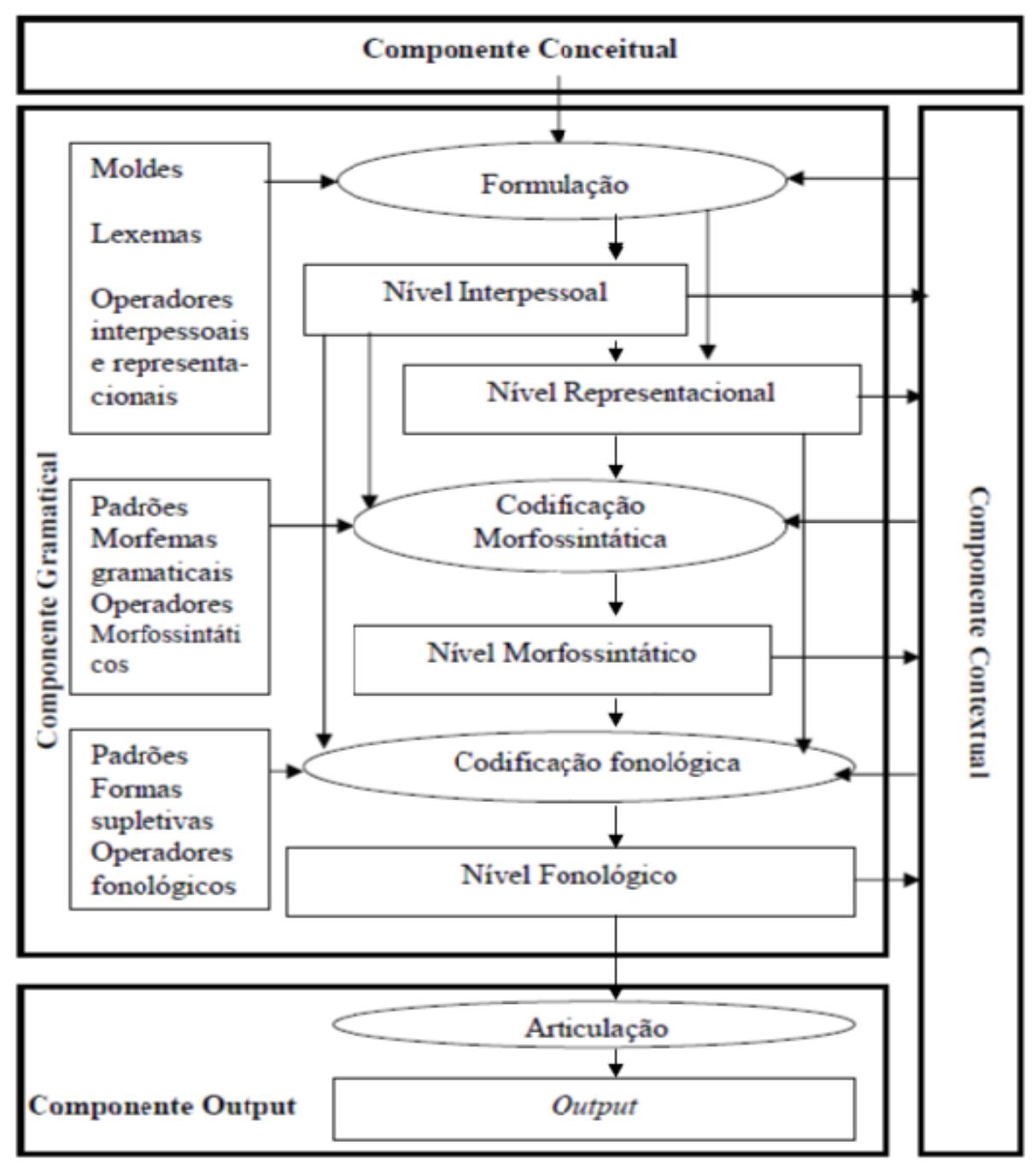

Figura 1. Esquema Geral da Gramática Discursivo-Funcional

Fonte: Hengeveld e Mackenzie (2008, p. 13)

Este trabalho trata, fundamentalmente, das relações estabelecidas em âmbito pragmático entre dois Atos Discursivos - menores unidades linguísticas identificáveis do comportamento comunicativo - que são arranjados pelo falante de modo a favorecêlo no alcance de suas expectativas interacionais, isto é, fruto da relação que estabelece com seu interlocutor.

Nesse âmbito, esta investigação tem por objetivo fornecer uma descrição das propriedades pragmático-semânticas, bem como das de cunho morfossintático e fonológico, de estruturas oracionais e sintagmáticas iniciadas por além de.

O universo de investigação é constituído por ocorrências reais de uso extraídas do córpus "Português oral", desenvolvido no âmbito do projeto "Português Falado: Variedades Geográficas e Sociais", organizado pelo Centro de Linguística da Universidade de Lisboa, em parceria com a Universidade de Toulouse-le-Mirail e a Universidade de Provença-Aix-Marselha. Cada ocorrência utilizada para exemplificação pode ser identificada por meio das informações sobre país, ano e título do inquérito, dispostas, nessa sequência, ao final do trecho, entre parênteses. Os casos em que essa identificação está ausente correspondem a paráfrases da ocorrência padrão, em que 
foram aplicados testes específicos, a partir de diretrizes teórico-metodológicas próprias da GDF, que permitem verificar, mais adequadamente, determinadas propriedades pragmáticas e semânticas do exemplo.

A análise apresentada tem por propósito contemplar os dados a partir de um panorama qualitativo e não quantitativo. Essa opção se justifica, principalmente, pelo fato de não se tratar de uma pesquisa de cunho sociolinguístico, embora contemple dados de diferentes variedades do português. Assim, a adoção de um viés exclusivamente qualitativo de contemplação dos dados em nada afeta os propósitos desta investigação, já que permite caracterizar adequadamente a forma de atuação das construções além de antepostas no português, que refletem intenções pragmáticas do âmbito da relação falante-ouvinte.

Com a finalidade de relacionar dados empíricos a bases teóricas de natureza funcional, cada uma das ocorrências levantadas foi analisada em função: (i) das camadas de cada um dos níveis previstos pela teoria: (ii) de seu estatuto informacional, ou seja, se veicula uma informação dada ou nova; (iii) da posição que ocupa em relação ao núcleo e (iv) do tempo e modo verbais da oração além de, nos casos oracionais.

\section{Construções com além de e a função retórica Suporte}

As ocorrências levantadas no córpus atestam a existência de estruturas sintagmáticas e oracionais iniciadas por além de que podem situar-se antes ou depois de seu núcleo. Este trabalho, no entanto, propõe-se a analisar apenas os casos de estrutura além de que se antepõem à oração núcleo, uma vez que, como veremos, esse traço marca uma função no desenvolvimento do discurso, ou seja, uma função retórica, conforme se observa em (5). Construções pospostas, diferentemente das antepostas, são formuladas no Nível Representacional e desempenham uma função semântica.

Nas construções antepostas, como a ilustrada em (5), a estrutura introduzida por além de traz uma informação anteriormente dada, que serve de suporte para a apresentação de outra informação que o falante considera mais relevante.

(5) - foi quando a gente combinou com o professor de matemática, a gente sempre brinca "ó, vamos num churrasco? vamos numa pizzaria?" e aquele dia realmente a gente combinou sério de ir. até ele falar "ah! mas é hoje que a gente vai?" a gente falar "se você não quiser ir hoje não tem problema." de repente todo mundo se animou. não foi a classe inteira, é lógico, que a gente não combinou com a classe inteira, mas foi o Tabajara, eu e alguns alunos. de repente a hora que a gente estava na pizzaria, eu não me, eu não me lembro, ali perto da, da,

$-[\ldots]$

- da escola mesmo...

- ah! sei qual que é [...]

- Trattoria acho que é. aí nisso ia passando a Rosires, que é nossa directora, a Eliana, a Maria, não é, que é de inglês, aí a gente chamou todos eles lá dentro, foi maravilhoso. aquilo que era para ser só uma cervejinha que era o combinado acabou assim saindo em pizza, não é, acabou em pizza como fala o ditado realmente. e ficamos ali até meia noite e meia, quer dizer, cada um tinha seu compromisso, seu, a esposa esperando, eu não, é lógico, mas eles tinham e foi muito gostoso porque a partir dali nasceu uma amizade mais gostosa com o professor. além de ele ser o professor, ele foi o amigo da gente. (Bra93:FestaEstudante) 
Em (5), o referente professor de matemática, já introduzido pelo falante no discurso é, depois, retomado na construção além de. Da mesma maneira, neste exemplo, a oração núcleo ele foi o amigo da gente também comporta uma informação anteriormente dada, tendo em vista que o falante já havia apontado que a partir dali nasceu uma amizade. Entretanto, nota-se que, mesmo comportando referentes já apresentados, ambas as orações não apresentam o mesmo estatuto discursivo. Isso se justifica pela maneira como o falante escolhe introduzi-los novamente no discurso: ao escolher retomar, primeiramente, o fato de ser professor, há uma opção pela informação mais previsível dentro desse contexto discursivo, uma vez que o inquérito trata, primordialmente, de relações que ocorrem no âmbito escolar, das interações professoraluno. Dessa maneira, apesar de ambas as informações mobilizadas, tanto na oração núcleo, quanto na oração além de, serem de conhecimento do interlocutor, uma delas é por ele considerada mais relevante, e por isso introduzida na oração núcleo para a qual a oração além de serve de suporte. Esse tipo de escolha por parte do falante corresponde a uma estratégia para que o objetivo comunicativo seja atingido, o que configura, portanto, uma ação no Nível Interpessoal, em que são formuladas as intenções comunicativas.

A mesma ação linguística pode ser observada em (6), em que as informações veiculadas pelas duas orações envolvidas na construção não mantêm uma relação de continuidade lógica, já que o fato de jogar de graça não pressupõe uma relação necessária com alimentar os jogadores. Contribui consideravelmente, no entanto, para a argumentação, tendo em vista que tal discrepância entre as informações apresentadas mostra que, ao escolher expressar primeiramente a informação dada, o falante ressalta aquela que, para ele, tem maior peso argumentativo.

$$
\begin{aligned}
& \text { Além de jogarmos de graça, ainda alimentávamos os jogadores. } \\
& \text { (PT97:DesportoDinheiro) }
\end{aligned}
$$

No Nível Interpessoal, a camada mais alta é o Movimento, considerado a maior unidade relevante para a análise gramatical, e se caracteriza por constituir uma contribuição autônoma para o desenvolvimento da interação. $O$ núcleo de cada Movimento pode ser composto por um ou mais Atos Discursivos, ou seja, as menores unidades linguísticas identificáveis do comportamento comunicativo. A construção além de ser o professor, ele foi o amigo da gente, exemplificada em (5), corresponde a dois Atos Discursivos que formam, ao lado de outros Atos, um Movimento. O mesmo se pode dizer de (6), em que o Movimento é constituído dos Atos Discursivos além de jogarmos de graça e ainda alimentávamos os jogadores. Contudo, como é possível verificar em (7), o estatuto de Atos Discursivos das partes envolvidas na construção não se altera, mesmo que a estrutura iniciada por além de seja um sintagma; dessa maneira, entende-se que o sintagma além da classificação e do estudo dos cartógrafos também compreende um Ato Discursivo, assim como seu núcleo há que saber também como é que as faziam:

além da classificação e do estudo dos cartógrafos [...] há que saber também como é que as faziam (PT89:CartografiaPortuguesa)

A relação entre os Atos dentro de um Movimento pode ser de equipolência ou de dependência. Nas relações de equipolência, o falante atribui aos Atos Discursivos o mesmo estatuto discursivo; por outro lado, nas relações de dependência, os Atos 
apresentam estatuto comunicativo distinto e, portanto, um Ato é considerado nuclear e o outro, subsidiário. Nas ocorrências (5), (6) e (7), por servirem de suporte, os Atos além de ser o professor, além de jogarmos de graça e além da classificação e do estudo dos cartógrafos constituem os Atos Subsidiários, enquanto ele foi o amigo da gente, ainda alimentávamos os jogadores e há que saber também como é que as faziam, que veiculam a informação mais relevante do ponto de vista do falante, são Atos Nucleares.

Nessa perspectiva, é possível afirmar que a força argumentativa da informação apresentada no Ato Nuclear se constrói a partir do apoio em outra informação anteriormente apresentada na construção além de, que constitui o Ato Subsidiário. Essa relação entre o Ato Nuclear e o Subsidiário não instaura uma simples adição de eventos semanticamente distintos, mas principalmente estabelece, entre tais eventos, uma relação de dependência no plano pragmático, portanto, da interação entre Falante e Destinatário. Ao selecionar, no Nível Interpessoal, a informação que deseja veicular por meio desse tipo de estrutura, o falante atribui aos Atos estatutos comunicativos distintos e, assim, instaura uma hierarquia entre essas unidades. Esse tipo de estratégia argumentativa proposital do falante para atingir seu objetivo comunicativo corresponde ao que a GDF denomina função retórica.

Entende-se que a retórica está fundamentalmente relacionada às propriedades formais de enunciados que influenciam o destinatário a aceitar os propósitos do falante e aos modos pelos quais ele ordena os componentes de um discurso para a realização de sua estratégia comunicativa. Os aspectos de unidades linguísticas que refletem a estruturação global do discurso são considerados funções retóricas que se aplicam a Atos Discursivos, uma das camadas do Nível Interpessoal. É exatamente isso que acontece na relação de dependência aqui tratada.

A essa relação denominamos função retórica Suporte, que propomos seja considerada juntamente com as outras funções retóricas previstas na GDF, dentre elas, Orientação, Correção, Motivação, Concessão e Aposição. Vejamos, então, as propriedades dessa função.

O estatuto de Atos Discursivos de cada uma das unidades envolvidas na construção com além de é comprovado pela possibilidade de apresentarem ilocuções diferentes, como mostram (5)a e (5)b, em que é possível atribuir às unidades forças ilocucionárias distintas, ficando o Ato Subsidiário sempre com ilocução declarativa, e o Nuclear com ilocução interrogativa (a) ou exclamativa (b):

(5)a além de ele ser o professor, ele foi o amigo da gente?

(5)b além de ele ser o professor, ele foi o amigo da gente!

Além disso, na condição de Atos Discursivos, essas unidades podem ainda ser restringidas por modificadores específicos dessa camada, tais como os de sequenciação e exemplificação, como se nota pela modificação que (7) sofre em (7)a, em que o Ato Subsidiário e o Nuclear são, respectivamente, restringidos pelos modificadores por exemplo e em resumo:

(7) além da classificação e do estudo dos cartógrafos que elaboraram essa, ah, da vida desses cartógrafos, [...] há que saber também como é que as faziam (..) (PT89:CartografiaPortuguesa) 
(7)a além da classificação e do estudo dos cartógrafos, há que saber também, por exemplo, como é que as faziam.

(7)b além da classificação e do estudo dos cartógrafos, em resumo, há que saber também como é que as faziam.

Esses Atos podem ser restringidos também por marcadores de ênfase, como os termos caramba e pô em (7)c e (7)d:

(7)c além da classificação e do estudo dos cartógrafos, caramba, há que saber também como é que as faziam.

(7)d além da classificação e do estudo dos cartógrafos, há que saber também como é que as faziam, $p \hat{o}$.

No Nível Representacional, o Ato Nuclear é representado como um Conteúdo Proposicional, e o Subsidiário, como um Estado-de-coisas. Conteúdos Proposicionais, como já observado, são construtos mentais, que podem ser avaliados em termos de sua verdade, mas que, por outro lado, não podem ser localizados nem no tempo e nem no espaço. Dada sua natureza, Conteúdos Proposicionais podem ser avaliados em termos de atitudes proposicionais, tais como dúvida, certeza, descrença etc., o que pode ser observado pela possibilidade de se restringirem tais conteúdos por meio de modificadores que indicam uma avaliação do falante, como faz o modificador com certeza, conforme mostra (5)c.

(5)c além de ele ser o professor, com certeza ele foi o amigo da gente.

Em (5)c, fica evidente que a avaliação do falante recai sobre o fato de o professor ser amigo, expresso na oração núcleo, que representa, por sua vez, a crença do falante de que um professor que participa das confraternizações com seus alunos pode ser considerado amigo da turma.

De acordo com a GDF, o Conteúdo Proposicional, por meio do qual o Ato Nuclear é codificado no Nível Representacional, é formado por um Episódio. A camada do Episódio pode ser constituída de um ou mais Estados-de-coisas que apresenta(m) continuidade em termos de Tempo, Locação e Indivíduos e, ao contrário da camada do Estado-de-coisas, que pode ser localizada no tempo relativo, pode apenas ser localizada no tempo absoluto.

Outra distinção relevante entre as camadas do Episódio e do Estado-de-coisas envolve, primordialmente, aspectos relacionados à finitude dos eventos. Como se verifica em (5), o evento codificado na camada do Conteúdo Proposicional - ele foi o amigo da gente - é localizado no tempo passado - especificamente, pretérito perfeito por meio do operador de tempo absoluto Pass, inserido na camada do Episódio que compõe esse Conteúdo Proposicional. Já o evento representado pelo Ato Subsidiário além de ele ser o professor - é um Estado-de-coisas, ou seja, uma unidade que pode ser localizada no tempo relativo, avaliada em termos de sua realidade, ser dita "(não) ocorrer", "(não) acontecer" ou "(não) ser o caso". Na construção em questão, este Estado-de-coisas não se encontra situado no tempo, tendo em vista que é expresso por um verbo não-finito, sendo, portanto, atemporal: "ser professor" caracteriza-se como uma atividade cuja existência não está vinculada a um tempo. Dessa maneira, uma vez 
que Conteúdos Proposicionais não se submetem à localização temporal, é na camada do Episódio que se marca o tempo do evento. Isso pode ser visto como uma comprovação não só da existência da camada do Episódio, como também de sua relevância para línguas como o português, o que tem sido questionado por alguns estudiosos.

A ocorrência (8) reforça esse aspecto, uma vez que a oração iniciada por além de, estando no infinitivo, assume o tempo absoluto (vai ter (de) saber resolver) expresso no verbo da oração nuclear, que se encontra no futuro e é modificado pelo deôntico ter que. Assim, o conjunto formado pelo Estado-de-Coisas introduzido por além de e pelo Estado-de-Coisas nuclear representa um Episódio, cuja localização temporal é dada pelo tempo absoluto expresso no Estado-de-Coisas nuclear.

(8) -> então, é. ele, então, aí vai para o costume, tem o costume, a, que eles falam, a analogia, que, por exemplo, se tem uma lei que, ah, fala sobre a, f[...], fala sobre uma coisa mas não é bem isso que tem, que cabe ao, o facto que ocorreu, certo, aí ele pode fazer analogia dessa lei, quer dizer, fazer, dar um jeito nessa lei para ela caber dentro do que está acontecendo, sabe, então isso, quer dizer, Direito é difícil, não é, porque além de você ter que saber as leis, você vai ter reso[...], saber resolver problema que nem previsto é nem nada. (Bra80:MundoDireito)

Dessa maneira, entende-se que as questões relacionadas à finitude, representada pela localização temporal do evento, e à não-finitude são fundamentais à distinção entre as camadas do Nível Representacional, uma vez que apenas a camada do Episódio comporta a localização temporal, responsável por situar o evento no tempo absoluto, o que é fundamental em línguas como o português, em que o tempo é primordialmente marcado no verbo e, em segunda instância, pelo advérbio, no caso de orações com verbos na forma não finita.

Tendo em vista a hierarquia do modelo teórico e, portanto, o fato de que uma camada mais alta comporta as camadas mais baixas, nas construções além de o núcleo do Estado-de-coisas será sempre um esquema de predicação, ou seja, um núcleo de cunho configuracional, o que significa afirmar que a oração introduzida além de corresponde, portanto, sempre a uma Propriedade Configuracional, constituída de um predicado, representado pela palavra além, que estabelece uma relação com seu argumento, por meio da preposição de.

No Nível Morfossintático, os atos Subsidiário e Nuclear constituem, juntos, a camada mais alta deste nível, a da Expressão Linguística. Essa camada refere-se a qualquer conjunto, em que ao menos uma unidade pode ser utilizada de forma independente; quando uma Expressão Linguística for formada por mais de uma unidade, elas pertencerão morfossintaticamente uma a outra, embora uma não seja parte da outra. Dessa maneira, a relação entre os constituintes que ocorrem nessa camada é definida em função do tipo de dependência existente entre eles. Nos processos de Cossubordinação e Extraoracionalidade, instaura-se uma dependência unilateral, uma vez que apenas uma das unidades pode ser usada independentemente.

As ocorrências obtidas no levantamento dos dados mostram que as construções objeto deste estudo podem ser codificadas na forma de uma Expressão Linguística constituída de duas Orações, como mostra (5), ou de um Sintagma e de uma Oração, como mostra (7), ambas repetidas por conveniência: 
além de ele ser o professor, ele foi o amigo da gente. (Bra93:FestaEstudante)

(7) porque além da classificação e do estudo dos cartógrafos [...] há que saber também como é que as faziam (PT89:CartografiaPortuguesa)

Como se pode observar, a oração além de ele ser o professor não pode ocorrer sozinha, contudo, não é um constituinte da oração ele foi o amigo da gente, que pode ocorrer de forma autônoma. Neste caso, morfossintaticamente, estabelece-se entre os pares constituintes da Expressão Linguística uma relação de Cossubordinação, já que ocorre entre orações.

Da mesma maneira, em (7) não se estabelece uma relação de mútua dependência entre o Sintagma além da classificação e do estudo dos cartógrafos e a Oração há que saber também como é que as faziam, uma vez que esta pode ocorrer independentemente daquele. Essa relação que evidencia a dependência de apenas um constituinte, quando ocorre entre um Sintagma e uma Oração configura o fenômeno da Extraoracionalidade.

Um aspecto importantíssimo a ser observado com relação a essa estrutura com além de é que, no Nível Morfossintático, o Ato Discursivo Subsidiário com a função retórica Suporte será sempre codificado na posição anterior ao Ato Nuclear, que comporta a informação considerada mais relevante, obedecendo assim ao Princípio de Iconicidade. Em outras palavras, ocupará sempre a posição $\mathrm{P}^{\text {pre }}$ da Expressão Linguística.

No Nível Fonológico, a construção além de é codificada como um Enunciado Fonológico que, por sua vez, comporta duas Frases Entonacionais, sendo cada uma delas caracterizada por um núcleo, ou seja, um ponto tonal localizado em uma ou mais sílabas, essencial para a sua interpretação como um todo. A separação entre essas Frases se dá por meio de pausas, neste caso, menores do que as que distinguem Enunciados.

\section{Considerações finais}

Esse trabalho buscou caracterizar a atuação de construções iniciadas por além de no português, codificadas na forma de sintagma ou oração, a partir da descrição de suas propriedades pragmáticas, semânticas, morfossintáticas e fonológicas.

Dessa forma, entende-se, nessa análise, que tanto sintagmas quanto orações iniciados por além de, alocados em posição inicial, caracterizam-se por atuarem como sustentação para informação veiculada na oração seguinte. Isso revela que a estrutura além de serve como apoio para a consolidação da força argumentativa da informação disposta na estrutura nuclear e, assim, instaura-se, entre as partes, uma dependência pragmática. Uma vez que esse tipo de recurso constitui uma estratégia proposital do falante, que visa a atingir determinados objetivos comunicativos, entende-se que esse tipo de construção veicula uma função retórica, aqui denominada Suporte.

Nesse âmbito, pode-se caracterizar a estrutura com função retórica Suporte da seguinte maneira: é atribuída a um Ato Discursivo Subsidiário, que traz sempre uma informação dada, e, no Nível Representacional, corresponde a um Estado-de-coisas, constituído de um predicado monovalente, representado por além e seu argumento. Morfossintaticamente, pode ser estruturado em forma de uma oração, com verbo não finito, ou de um sintagma, que obrigatoriamente se posiciona antes da oração núcleo, e fonologicamente constitui um Enunciado. 


\section{REFERÊNCIAS}

BECHARA, E. Moderna Gramática Portuguesa. Rio de Janeiro: Lucerna, 2004.

BUTLER, C. S. Structure and function: a guide to three major structural functional theories. Part 1: approaches to the simple clause. Amsterdam; Philadelphia: J. Benjamins, 2003.

CAMACHO, R. G. Estruturas coordenadas aditivas. In: NEVES, M. H. M. (Org.). Gramática do Português Falado. v. VII: Novos Estudos. São Paulo: Humanitas/FAPESP; Campinas: Editora da UNICAMP, 1999. p. 351-405.

COMRIE, B. Tense. (Cambridge Textbooks in Linguistics). Cambridge: Cambridge University Press, 1985.

CUNHA, C. Gramática do português contemporâneo. Belo Horizonte: Berbado Álvares S. A., 1970.

CUNHA, C. F.; CINTRA, L. Nova gramática do português contemporâneo. 2. ed. Rio de Janeiro: Nova Fronteira, 1985.

. Nova gramática do português contemporâneo. 3. ed. Rio de Janeiro: Nova Fronteira, 2001.

HALliDAY, M. A. K. An Introduction to Functional Grammar. London: Edward, Arnold Publishers, 1985.

HENGEVELD, K. Adverbial clauses in the languages of Europe. In: VAN DER AUWERA, J. Adverbial construction in the languages of Europe. New York: Mouton de Gruyter, 1998. p. 335-419.

HENGEVELD, K.; MACKENZIE, J. L. Functional Discourse Grammar: A typologically based theory of language structure. Oxford: Oxford University Press, 2008.

KURY, A. da G. Novas lições de análise sintática. São Paulo: Ática, 1987.

MATHIESSEN, C.; THOMPSON, S. A. The structure of discourse and subordination. In: HAIMAN, J.; THOMPSON, S. A. (Ed.). Clause Combining in Grammar and Discourse. Amsterdam: John Benjamins, 1988. p. 275-329.

MÓDOLO, M. A estrutura aditiva "não só... mas também" de uma perspectiva multissistêmica. Estudos Linguísticos, XXXIV, p. 171-176, 2005.

NEVES, M. H. de M. Gramática de usos do português. São Paulo: Editora UNESP, 1999.

OLIVEIRA, T. P. A Hipotaxe de Adição. Revista do GEL, São Paulo, v. 9, n. 2, p. 25$45,2012 \mathrm{a}$.

A Oração Subordinada de Adição. Estudos Linguísticos. São Paulo, v. 41, n. 1, p. $90-100,2012$ b.

PENHAVEL, E. Multifuncionalidade e níveis de análise: o papel do conectivo "e" na organização do discurso. 2005. 132 f. Dissertação (Mestrado em Análise Linguística) Instituto de Biociências, Letras e Ciências Exatas, Universidade Estadual Paulista "Júlio de Mesquita Filho", São José do Rio Preto, 2005. 
PÉREZ QUINTERO, M. J. Adverbial Subordination in English: A Functionalist Approach. Amsterdam/New York: Rodopi, 2002.

PEZATTI, E. G. A Ordem de Palavras no Português. São Paulo: Parábola Editorial, 2014.

Recebido em: 30/08/2017

Aprovado em: 15/05/2018 